This is the author's final, peer-reviewed manuscript as accepted for publication. The publisher-formatted version may be available through the publisher's web site or your institution's library.

\title{
Variation in susceptibility of laboratory and field strains of three stored-grain insect species to $\beta$-cyfluthrin and chlorpyrifos-methyl plus deltamethrin applied to concrete surfaces
}

Blossom Sehgal, Bhadriraju Subramanyam, Frank H. Arthur, and Bikram S. Gill

\section{How to cite this manuscript}

If you make reference to this version of the manuscript, use the following information:

Sehgal, B., Subramanyam, B., Arthur, F. H., \& Gill, B. S. (2014). Variation in susceptibility of laboratory and field strains of three stored-grain insect species to $\beta$ cyfluthrin and chlorpyrifos-methyl plus deltamethrin applied to concrete surfaces. Retrieved from http://krex.ksu.edu

\section{Published Version Information}

Citation: Sehgal, B., Subramanyam, B., Arthur, F. H., \& Gill, B. S. (2014). Variation in susceptibility of laboratory and field strains of three stored-grain insect species to $\beta$ cyfluthrin and chlorpyrifos-methyl plus deltamethrin applied to concrete surfaces. Pest Management Science, 70(4), 576-587.

Copyright: @ 2013 Society of Chemical Industry

Digital Object Identifier (DOI): doi:10.1002/ps.3580

Publisher's Link: http://onlinelibrary.wiley.com/doi/10.1002/ps.3580/full

This item was retrieved from the K-State Research Exchange (K-REx), the institutional repository of Kansas State University. K-REx is available at http://krex.ksu.edu 
For: Pest Management Science

PM-13-0080, Revised version

Sehgal et al.: Efficacy of insecticides used for empty bin treatments

\section{Variation in susceptibility of laboratory and field strains of three stored-grain insect species to $\beta$-cyfluthrin and chlorpyrifos-methyl plus deltamethrin applied to concrete surfaces}

Blossom Sehgal, ${ }^{\mathrm{a}}$ Bhadriraju Subramanyam, ${ }^{\mathrm{a}^{*}}$, Frank H. Arthur, ${ }^{\mathrm{b}}$ and Bikram S. Gill ${ }^{\mathrm{c}}$

${ }^{\mathrm{a} D e p a r t m e n t ~ o f ~ G r a i n ~ S c i e n c e ~ a n d ~ I n d u s t r y, ~ K a n s a s ~ S t a t e ~ U n i v e r s i t y, ~ M a n h a t t a n, ~ K a n s a s ~ 66506, ~}$ USA

${ }^{\mathrm{b} U S D A}$,ARS, Center for Grain and Animal Health Research, Manhattan, KS 66502, USA

${ }^{c}$ Department of Plant Pathology, Kansas State University, Manhattan, Kansas 66506, USA

*Correspondence to: Bhadriraju Subramanyam, Department of Grain Science and Industry, 201

Shellenberber Hall, Kansas State University, Manhattan, Kansas 66506, USA.

E-mail: sbhadrir@k-state.edu 


\begin{abstract}
BACKGROUND: The efficacy of commercial formulations of $\beta$-cyfluthrin and chlorpyrifosmethyl plus deltamethrin applied to clean, concrete surfaces similar to that of empty bins against field strains of stored-grain insects is unknown. We exposed adults of 16 strains of the red flour beetle, Tribolium castaneum (Herbst); 8 strains of the sawtoothed grain beetle, Oryzaephilus surinamensis (L.); and 2 strains of the lesser grain borer, Rhyzopertha dominica (F.), collected mainly from farm-stored grain in Kansas, USA, to $\beta$-cyfluthrin and chlorpyrifos-methyl plus deltamethrin applied to concrete surfaces and determined knockdown and mortality.

RESULTS: Knockdown and mortality differences among species and strains to the insecticides tested were significant. Mortality of all species was less than that of knockdown, suggesting recovery when placed on food after insecticide exposure. $\beta$-cyfluthrin was effective against $R$. dominica but ineffective against $T$. castaneum and $O$. surinamensis field strains. Chlorpyrifosmethyl plus deltamethrin was only partially effective against field strains of the three species. CONCLUSION: Reduced susceptibility in field strains may be due to inherent formulation deficiency and low levels of tolerance or resistance to $\beta$-cyfluthrin. No single insecticide provided adequate control of the three species tested.
\end{abstract}

Keywords: insecticides, empty-bin treatments, stored-grain insects, field strains, efficacy assessment 


\section{INTRODUCTION}

Stored-grain insect management, prior to storing newly harvested grain, begins with removing residual grain debris and application of an approved insecticide to the concrete floor and interior bin surfaces to kill any live insects present. This practice is followed by $78.8 \%$ of the 318 Kansas producers storing wheat who responded to a survey in $1987 .{ }^{1}$ Among the insecticides currently registered by the United States Environmental Protection Agency (US-EPA) for empty bin treatments, $\beta$-cyfluthrin or Tempo ${ }^{\circledR}$ SC Ultra (Bayer CropScience, Research Triangle Park, NC, USA), is new and an alternative to traditionally used cyfluthrin wettable powder (WP) and emulsifiable concentrate (EC) formulations. $\beta$-cyfluthrin can be applied to surfaces at low and high application rates of 0.01 and $0.02 \mathrm{~g}(\mathrm{AI}) \mathrm{m}^{-2}$, respectively. These rates are $50 \%$ less than that of the WP or EC formulations. Chlorpyrifos-methyl at $3 \mathrm{ppm}$ plus deltamethrin at $0.5 \mathrm{ppm}$ (Storcide ${ }^{\mathrm{TM}}$ II, Bayer CropScience) was registered in 2004 for direct treatment of barley, oats, rice, sorghum, and wheat intended for storage and for empty bins receiving these grains. This combination product replaced chlorpyrifos-methyl after its tolerances were revoked.

The efficacy of the WP and EC formulations of cyfluthrin at low $\left(0.02 \mathrm{~g}[\mathrm{AI}] \mathrm{m}^{-2}\right)$ and high $\left(0.04 \mathrm{~g}[\mathrm{AI}] \mathrm{m}^{-2}\right)$ labeled rates was evaluated on concrete surfaces against laboratory populations of the red flour beetle, Tribolium castaneum (Herbst); confused flour beetle, Tribolium confusum Jacquelin du Val; and Indianmeal moth, Plodia interpunctella (Hübner). ${ }^{2-6}$ The WP formulation was more effective than the EC formulation against adults of Tribolium spp. probably due to greater availability of residues on treated surfaces. ${ }^{7}$ Additionally, the WP formulation was more persistent than the EC on both steel ${ }^{8}$ and concrete surfaces. ${ }^{2}$ Exposure of T. castaneum adults to the low rate of cyfluthrin WP on concrete surfaces for 0.5 to $4 \mathrm{~h}$ in the absence of flour resulted in $100 \%$ mortality; similar mortality at the high rate occurred only after 
$2 \mathrm{~h}$ of exposure. ${ }^{3}$ If $T$. castaneum adults were provided $1 \mathrm{~g}$ of flour for $1 \mathrm{wk}$ after a $2 \mathrm{~h}$ of exposure to the low rate of cyfluthrin WP, $40 \%$ of the adults recovered. ${ }^{4}$ In another study, $T$. castaneum adults exposed for $2 \mathrm{~h}$ on concrete surfaces treated with low rate of cyfluthrin WP and then transferred to concrete dishes for $1 \mathrm{wk}$ showed $60 \%$ mortality in the absence of food, $49 \%$ in the presence of $1 \mathrm{~g}$ of wheat kernels, $15 \%$ in $1 \mathrm{~g}$ of sawdust, and $5 \%$ in $1 \mathrm{~g}$ of flour. ${ }^{9}$ Differences in insect responses in the presence of flour between the two studies may be attributed to the temperatures used. The former test ${ }^{4}$ was conducted at $22^{\circ} \mathrm{C}$ and the latter at $28^{\circ} \mathrm{C}{ }^{9}$ Pyrethroids such as cyfluthrin generally are known to have a negative temperature coefficient. For example, the toxicity of cyfluthrin to T. castaneum adults was found to decrease markedly at 25,30 and $35^{\circ} \mathrm{C}$ when compared with $20^{\circ} \mathrm{C} .{ }^{10}$ Limited studies were conducted with the new $\beta$-cyfluthrin formulation. $\beta$-cyfluthrin was found to be effective against the storedproduct psocid species on concrete at a rate of $2.4 \mathrm{mg}(\mathrm{AI}) \mathrm{m}^{-2}$ at $30^{\circ} \mathrm{C}$ and $70 \%$ r.h. ${ }^{11}$ The efficacy of $\beta$-cyfluthrin against stored-product insects other than psocids has not been studied.

Chlorpyrifos-methyl plus deltamethrin was effective against several stored-grain psocids on stored wheat. ${ }^{12}$ It was also effective against the lesser grain borer, Rhyzopertha dominica (F.); rice weevil, Sitophilus oryzae (L.); T. castaneum, and P. interpunctella on stored wheat, and against $R$. dominica and S. oryzae on short-grain and long-grain rices, ${ }^{13}$ but studies on its efficacy as a surface treatment are lacking.

All of the studies mentioned above were conducted using laboratory reared stored-grain insects. Field collected insects may differ markedly from laboratory strains in their susceptibility to insecticides applied to empty bins and grains due to natural tolerance or resistance. ${ }^{14-18}$ To date, there are no published studies documenting effectiveness of $\beta$-cyfluthrin and chlorpyrifosmethyl plus deltamethrin on concrete surfaces similar to that of empty bins against field strains 
of stored-grain insect populations. Such an evaluation is necessary to confirm whether or not an approved insecticide will work in practical field situations at the labeled rates. In the present investigation, we determined susceptibility of adults of T. castaneum, O. surinamensis, and $R$. dominica field strains from the United States to $\beta$-cyfluthrin and chlorpyrifos-methyl plus deltamethrin applied to concrete surfaces in the laboratory.

\section{MATERIALS AND METHODS}

\subsection{Collection of field strains}

Cooperating farm sites (Table 1) were visited on one to three occasions between July and November 2011 to collect adults of T. castaneum, O. surinamensis and R. dominica from farm bins in Kansas by inserting five perforated probe traps ${ }^{19}$ just below the grain surface to capture live adults of insect species. These traps were removed after 1 to $2 \mathrm{wk}$. Additionally, 1 to $2 \mathrm{~kg}$ sample of mostly wheat, and some corn and sorghum, were collected in $30.5 \mathrm{~cm}$ wide and 37.5 cm long plastic Ziploc bags (Assorted Bag Company, Dallas, TX, USA). In the laboratory, 2.38mm diameter aluminum sieves and pans (Seedburo Equipment Company, Des Plaines, IL, USA) were used to separate live adults of insects from grains. In addition, five strains of T. castaneum and one strain of $R$. dominica collected from flour mills in the United States prior to 2011 were also included in this study, along with the laboratory strains of each species, that have been in rearing, without insecticide exposure, since 1999 in the Department of Grain Science and Industry, Kansas State University. These laboratory strains served as the standard reference strains and assumed to be insecticide-susceptible. 


\subsection{Insect rearing}

Laboratory and field strains were reared on standard diets in a growth chamber at $28^{\circ} \mathrm{C}$ and $65 \%$ r.h., respectively. Organic white wheat flour (Heartland Mills, Marienthal, KS, USA) plus 5\% (by wt) brewer's yeast diet was used for rearing T. castaneum, while clean organic hard red winter wheat (Heartland Mills, Marienthal, KS, USA) and rolled oats plus 5\% brewer's yeast diet were used for rearing $R$. dominica and $O$. surinamensis, respectively.

\subsection{Concrete-poured Petri dishes}

Ready-mix concrete (Rockite, Hartline Products Co., Inc., Cleveland, OH, USA) was mixed with tap water to make a slurry. This slurry was poured into $9 \mathrm{~cm}$ diameter, $1.5 \mathrm{~cm}$ high, and $62 \mathrm{~cm}^{2}$ area plastic Petri dishes (Fisher Scientific, Denver, CO, USA). Concrete $(3,810 \mathrm{~g})$ was mixed with $1,905 \mathrm{ml}$ of tap water to make 100 dishes. The slurry was allowed to dry and the inside walls of the Petri dishes were coated with polytetrafluoroethylene (Insecta-a-Slip, Bio Quip Products, Inc., Rancho Dominguez, CA, USA) to prevent insects from crawling on the sides of dishes.

\subsection{Treatment of concrete dishes with insecticides}

$\beta$-cyfluthrin (11.8\% purity) and chlorpyrifos-methyl plus deltamethrin (21.6 and 3.7\% purity), were supplied by Bayer CropScience and were diluted in distilled water. Concrete surfaces of dishes were treated with $\beta$-cyfluthrin at the low labeled rate of $0.01 \mathrm{~g} \mathrm{(AI)} \mathrm{m}^{-2}$ and the high labeled rate of $0.02 \mathrm{~g}(\mathrm{AI}) \mathrm{m}^{-2}$, and with chlorpyrifos-methyl plus deltamethrin at the labeled rate of 0.12 plus $0.02 \mathrm{~g}(\mathrm{AI}) \mathrm{m}^{-2}$ by applying $255 \mu 1$ spray solution per dish using a Badger 100 artist's airbrush (Model 100, Franklin Park, IL, USA). Dishes sprayed with $255 \mu 1$ of distilled water served as the control treatment. Treated dishes were allowed to dry under room conditions $\left(25^{\circ} \mathrm{C}\right.$ and $25 \%$ r.h. $)$ for $24 \mathrm{~h}$ before exposing insects. 


\subsection{Time-response tests with laboratory strains}

The laboratory strains of T. castaneum, O. surinamensis, and R. dominica were used to establish a time at which $100 \%$ or close to $100 \%$ knockdown and mortality of adults occurred when exposed to labeled rates of $\beta$-cyfluthrin and chlorpyrifos-methyl plus deltamethrin. This time was used to expose field strains of each species to concrete treated with the two insecticides. Ten unsexed (1- to 2-wk-old) adults each of T. castaneum, O. surinamensis, or $R$. dominica from laboratory cultures were introduced into each dish and the dishes were covered with Petri dish lids. Adults were exposed to treated dishes for 1, 2, 4, 8, 12, 16, 20 and $24 \mathrm{~h}$. Separate dishes were used for each time period. Each exposure time and species combination included an untreated control dish that was sprayed with aliquots of distilled water. Each species, insecticide, rate, and time combination, including the control treatment, was replicated three times. Dishes were arranged on a laboratory table and $\mathrm{HOBO}^{\circledR}$ data loggers (Onset Computer Corp., Bourne, MA, USA) indicated the mean $\pm \mathrm{SE}(n=4)$ temperature and relative humidity in the laboratory room during insect exposure were $24.3 \pm 0.04^{\circ} \mathrm{C}$ (range, $20.0-28.5^{\circ} \mathrm{C}$ ) and $23.4 \pm$ $0.06 \%$ r.h. (range, $15.0-31.3 \%$ ), respectively.

At each exposure time, adults of each species that were knocked down and active were counted. After counting, all adults were transferred to $150-\mathrm{ml}$ round plastic containers with $30 \mathrm{~g}$ of the respective insect diet. The plastic containers had perforated lids with wire-mesh screens to facilitate air diffusion. Containers were incubated at $28^{\circ} \mathrm{C}$ and $65 \%$ r.h. for 1 wk to determine end-point mortality following insect recovery on rearing diets.

\subsection{Exposure of field strains at labeled rates for a fixed time}

The time at which knockdown and mortality of adults was $100 \%$, or near $100 \%$, for a given species and insecticide combination was used to expose adults of field strains of stored grain 
insect species. Ten adults of each species and field strain, along with the corresponding laboratory strain, were tested following protocols mentioned above. The low labeled rate of $\beta$ cyfluthrin gave poor control of $T$. castaneum and $O$. surinamensis laboratory strains with mortalities of 47 and $83 \%$, respectively, at the maximum exposure time of $24 \mathrm{~h}$. Therefore, adults of these two species were exposed for $24 \mathrm{~h}$ to concrete treated only with the high labeled rate of $\beta$-cyfluthrin, while $R$. dominica was exposed to this insecticide for $2 \mathrm{~h}$ because of its high susceptibility. All three species were exposed for $8 \mathrm{~h}$ to concrete treated with chlorpyrifosmethyl plus deltamethrin. Each insecticide, species, and strain combination was replicated five times. Knockdown and mortality of field strains were determined as explained above. Tests with field strains of the three species and the laboratory strains were performed in the laboratory room where mean $\pm \operatorname{SE}(n=4)$ temperature and relative humidity were $25.4 \pm 0.02^{\circ} \mathrm{C}$ (range, 23.4 $26.9^{\circ} \mathrm{C}$ ) and $17.2 \pm 0.1 \%$ (range, $15.0-27.9 \%$ ), respectively, and also at constant conditions in a growth chamber at $28^{\circ} \mathrm{C}$ and $65 \%$ r.h. At room conditions, low mortality was observed, so the tests were also done at constant conditions to see if there was any temperature effect as these insecticides are applied to empty bins 3 to 4 wk prior to storing new grain after harvest during the summer months of June and July. At room conditions, each strain had its respective control treatment. At constant conditions only the laboratory strain served as the control for all strains because knockdown and mortality of field strains in the control treatments in tests at room conditions were less than $10 \%$.

\subsection{Dose-response tests with $\beta$-cyfluthrin on laboratory and least susceptible field strains}

Based on field strain responses to insecticides, three least susceptible strains of T. castaneum and two of $O$. surinamensis, along with corresponding laboratory strains, were exposed to $\beta$ cyfluthrin-treated concrete dishes at one to four times the high labeled rate $(0.02$ to $0.08 \mathrm{~g}$ [AI] 
$\mathrm{m}^{-2}$ ) to assess knockdown and mortality. Dishes sprayed with distilled water served as the control treatment for all strains. All dose-response tests were performed at $28^{\circ} \mathrm{C}$ and $65 \%$ r.h. There were five replications for each species, strain, and $\beta$-cyfluthrin rate combination, and 10 adults were exposed in each replication.

\subsection{Data analysis}

Adults of each species that were knocked down and those that died after $1 \mathrm{wk}$ recovery on diets out of the total exposed were calculated as a percentage. In the time-response tests with the laboratory strains, there was no knockdown and mortality in the control treatment for $T$.

castaneum and $R$. dominica during 1 to $24 \mathrm{~h}$ exposures. The maximum mean knockdown of $O$. surinamensis in the control treatment was $3 \%$ and mortality was $10 \%$. Therefore, knockdown and mortality data were not corrected for these responses in the control treatment. Linear $(y=a+$ $b x)$ or nonlinear $\left(y=a+b / x^{2}\right)$ models were fit to knockdown and mortality responses over time for each species of laboratory strains by insecticide and rate using Table Curve 2D software (Jandel Scientific, San Rafael, CA, USA). Models were not fit to data when knockdown or mortality was $100 \%$ at all exposure times; for example this occurred with $R$. dominica mortality and with $O$. surinamensis knockdown at both rates of $\beta$-cyfluthrin. Linear or nonlinear models fit to data allowed for statistical comparison of knockdown and mortality responses for each insect species and insecticide, and for comparison of knockdown or mortality responses between insecticides, between the two $\beta$-cyfluthrin rates, and between species by insecticide and rate. These pair-wise comparisons involved comparing individual models fit to data ${ }^{20}$ with a pooled model fit to data of the pairs being compared. ${ }^{21}$ Individual models were considered different from one another if the $F$-test showed the individual models deviated significantly $(P \leq 0.05)$ from the pooled model. 
The mean knockdown and mortality of all T. castaneum, O. surinamensis, and $R$. dominica field strains in the control treatment at room conditions ranged from 0 to $2 \%, 0$ to $7 \%$, and 0 to $4 \%$, respectively. So the knockdown and mortality data of field strains at room conditions were not corrected for these responses in the control treatment. At constant conditions, the mean mortality of $T$. castaneum in the control treatment was $0 \%$, but that of $O$. surinamensis and $R$. dominica was $14 \%$ and $21 \%$, respectively. Therefore, the mortality data of O. surinamensis and $R$. dominica at constant conditions were corrected for control mortality. ${ }^{22}$ The knockdown and mortality data of field strains at room and constant environmental conditions at established fixed times were analyzed by species after transformation to angular values $^{23}$ for normalizing heteroscedastic treatment variances. For each insecticide and species, knockdown or mortality data at room or constant conditions were analyzed by one-way analysis of variance (ANOVA), and Dunnett's procedure was used to determine if responses of each field strain differed from that of the corresponding laboratory strain. ${ }^{20}$

In dose-response tests with $\beta$-cyfluthrin at constant conditions, knockdown and mortality responses of $T$. castaneum and $O$. surinamensis strains were not corrected for the corresponding control responses as the mean knockdown was $0 \%$ and mortality ranged from 0 to $8 \%$ for strains of both species. Knockdown or mortality data for each species and strain were subjected to oneway ANOVA, and the least squares means test was used to determine differences $(P \leq 0.05)$ among the four $\beta$-cyfluthrin rates. 


\section{RESULTS}

\subsection{Time-mortality responses of laboratory strains}

Knockdown of $T$. castaneum adults during the 1 to $24 \mathrm{~h}$ exposures ranged from 20 to $100 \%$ at the low $\beta$-cyfluthrin rate and 43 to $100 \%$ at the high labeled rate (Fig. 1A). Mortality of $T$. castaneum adults at the low and high $\beta$-cyfluthrin rate increased linearly with time but never reached $100 \%$ (Fig. 1B). The increase in knockdown and mortality of T. castaneum adults with time when exposed to chlorpyrifos-methyl plus deltamethrin-treated concrete surfaces was nonlinear, and $100 \%$ knockdown and mortality were achieved at $4 \mathrm{~h}$ and $8 \mathrm{~h}$, respectively. Knockdown of O. surinamensis adults was $100 \%$ at all times when exposed to both the low and high labeled rates of $\beta$-cyfluthrin (Fig. 1C). Adult mortality increased in a nonlinear fashion and failed to reach $100 \%$ at the low rate, and reached $100 \%$ only with the high rate at $24 \mathrm{~h}$ (Fig. 1D). Complete knockdown of $O$. surinamensis adults occurred at $8 \mathrm{~h}$ (Fig. 1C) and complete mortality at $4 \mathrm{~h}$ (Fig. 1D) on chlorpyrifos-methyl plus deltamethrin-treated concrete. Unlike T. castaneum and $O$. surinamensis, adults of $R$. dominica were extremely susceptible to $\beta$-cyfluthrin, and all adults died at low and high $\beta$-cyfluthrin rates irrespective of the exposure time (Fig. 1F). However, with chlorpyrifos-methyl plus deltamethrin, mean knockdown and mortality at all exposure times ranged from 17 to $100 \%$ (Fig. 1E) and 7 to 100\% (Fig. 1F), respectively. Except for $R$. dominica adults exposed to $\beta$-cyfluthrin, adults of T. castaneum and $O$. surinamensis exposed to $\beta$-cyfluthrin and chlorpyrifos-methyl plus deltamethrin recovered when placed on diets. The overall recovery ranged from 0 to $76 \%$, and the degree of recovery did not follow any consistent trend as it varied with the species, exposure time, and insecticide.

Knockdown and mortality responses for each insect species-insecticide combination were satisfactorily described by linear or nonlinear models $\left(r^{2}=0.80-0.99\right)$ (Fig. 1A-F), and the 
model parameters are given in Table 2. Knockdown responses over time for T. castaneum exposed to $\beta$-cyfluthrin low and high rate were nonlinear, whereas mortality responses at each rate were linear. Therefore, for $\beta$-cyfluthrin, at each rate, statistical comparison between knockdown and mortality was not possible. Comparisons between knockdown and mortality at each $\beta$-cyfluthrin rate could not be made because of $100 \%$ mortality of $R$. dominica or $100 \%$ knockdown of $O$. surinamensis at all exposure times. Knockdown and mortality responses of $T$. castaneum, O. surinamensis, or R. dominica adults exposed to chlorpyrifos-methyl plus deltamethrin were not significantly different from one another $(F$, range among species $=0.94$ $3.30 ; \mathrm{df}=2,12 ; P$, range $=0.072-0.417)$.

$\beta$-cyfluthrin at the high rate caused significantly greater knockdown $(P<0.05)$ of $T$. castaneum adults than $\beta$-cyfluthrin low rate and chlorpyrifos-methyl plus deltamethrin (Table 3 ). Knockdown responses of $R$. dominica adults at $\beta$-cyfluthrin low and high rate were essentially similar $(P>0.05)$, but at each rate the knockdown responses were significantly greater $(P<$ 0.05) than that of chlorpyrifos-methyl plus deltamethrin. The high rate of $\beta$-cyfluthrin caused significantly greater mortality of $O$. surinamensis adults when compared with the low rate.

Knockdown responses of $R$. dominica exposed to $\beta$-cyfluthrin at the low or high rate were greater $(P<0.05)$ than that of $T$. castaneum (Table 4$)$. Knockdown responses of $O$. surinamensis exposed to chlorpyrifos-methyl plus deltamethrin were significantly greater $(P<$ 0.05) when compared with that of $T$. castaneum or $R$. dominica. Similarly, mortality responses of O. surinamensis were significantly greater $(P<0.05)$ than that of $R$. dominica but not $T$. castaneum. 


\subsection{Responses of field strains at room conditions}

The mean knockdown of all $T$. castaneum field strains exposed to the high rate of $\beta$-cyfluthrintreated concrete ranged from 90 to $98 \%$, and mean mortality ranged 16 to $67 \%$ (Fig. 2A) with recovery on diet ranging from 32 to $83 \%$. One-way ANOVA by insecticide showed that knockdown among $T$. castaneum strains exposed to the high rate of $\beta$-cyfluthrin was not significant $(F=1.56 ; \mathrm{df}=16,73 ; P=0.101)$, but mortality differences among strains were significant $(F=2.14 ; \mathrm{df}=16,73 ; P=0.015)$. Although ANOVA showed mortality differences

among strains, Dunnett's test ${ }^{20}$ showed that the mortality of each field strain did not differ significantly $(P>0.05)$ from that of the laboratory strain.

The mean knockdown of five of the seven $O$. surinamensis field strains exposed to $\beta$ cyfluthrin was $100 \%$, whereas it was $71 \%$ for $\mathrm{AB} 1$ and $76 \%$ for $\mathrm{AB} 2$ strain (Fig. $2 \mathrm{~B}$ ). The mean mortality for the five strains that showed $100 \%$ knockdown ranged from 86 to $100 \%$, whereas it was 36 and $49 \%$ for $\mathrm{AB} 1$ and $\mathrm{AB} 2$ strains, respectively, indicating recovery when placed on diet. The seven strains of $O$. surinamensis exposed to $\beta$-cyfluthrin showed significant differences in knockdown $(F=17.71 ; \mathrm{df}=7,32 ; P<0.0001)$ and mortality $(F=13.98 ; \mathrm{df}=7,31 ; P<0.0001)$. Knockdown and mortality responses of $\mathrm{AB} 1$ and $\mathrm{AB} 2$ field strains differed significantly from that of the laboratory strain $(P<0.05$; Dunnett's test $)$.

$\beta$-cyfluthrin was extremely effective against $R$. dominica field strains with more than 98\% knockdown and 100\% mortality (Fig. 2C). Knockdown responses among strains exposed to the high rate of $\beta$-cyfluthrin were not significantly different $(F=1.00 ; \mathrm{df}=2,14 ; P=0.397$ ).

The knockdown of 11 out of 16 T. castaneum field strains exposed to chlorpyrifos-methyl plus deltamethrin was greater than $90 \%$, and only eight strains had mortality greater than $90 \%$ (Fig. 2D). Mortality was less than $50 \%$ in $\mathrm{AB} 1$ and $\mathrm{KC}$ field strains, and the overall recovery on 
diet ranged from 0 to $50 \%$. One-way ANOVA showed significant differences among field strains in knockdown $(F=4.60 ; \mathrm{df}=16,73 ; P<0.0001)$ and mortality $(F=4.36 ; \mathrm{df}=16,73 ; P<$

0.0001). Knockdown response of $\mathrm{AB} 1$ strain and mortality of $\mathrm{AB} 1$ and $\mathrm{KC}$ strains differed from that of the laboratory strain $(P<0.05$; Dunnett's test $)$.

The mean knockdown of seven $O$. surinamensis field strains exposed to chlorpyrifosmethyl plus deltamethrin ranged from 68 to $96 \%$, and the mortality ranged from 38 to $98 \%$ with a recovery of 0 to $44 \%$ on diet (Fig. 2E). Field strains of $O$. surinamensis exposed to chlorpyrifos-methyl plus deltamethrin showed differences in knockdown $(F=2.67 ; \mathrm{df}=7,32 ; P$ $=0.027)$ and mortality $(F=5.33 ; \mathrm{df}=7,31 ; P=0.0004)$. Knockdown of $\mathrm{AB} 1$ strain and mortality of $\mathrm{AB} 1$ and $\mathrm{CF}$ strains were significantly different from that of the laboratory strain $(P$ $<0.05$; Dunnett's test).

The two field strains of $R$. dominica showed reduced susceptibility to chlorpyrifos-methyl plus deltamethrin (Fig. 2F), because knockdown ranged from 84 to $90 \%$ and mortality from 7 to $22 \%$. The recovery of the two field strains on diet ranged from 74 to $92 \%$. One-way ANOVA showed knockdown $(F=17.31 ; \mathrm{df}=2,12 ; P=0.0003)$ and mortality $(F=21.31 ; \mathrm{df}=2,12 ; P=$ 0.0001) responses of laboratory and two field strains (CF and RL) to be significantly different. Mortality responses of both the field strains differed significantly from that of the laboratory strain $(P<0.05$; Dunnett's test $)$.

\subsection{Responses of field strains at constant conditions}

$\beta$-cyfluthrin was less effective against T. castaneum field strains at constant conditions when compared with room conditions since knockdown was less than $90 \%$ in five of the 16 field strains and mortality was less than $51 \%$ in all strains including the laboratory strain (Fig.3A). In contrast, at room conditions knockdown of all strains was more than $90 \%$ and mortality of only 
11 strains was less than $50 \%$. There were significant differences among T. castaneum strains exposed to $\beta$-cyfluthrin in knockdown $(F=2.14 ; \mathrm{df}=16,68 ; P=0.016)$ and mortality $(F=2.26$; $\mathrm{df}=16,68 ; P=0.011)$.

The knockdown of six out of eight $O$. surinamensis field strains (one extra strain than those tested at room conditions) exposed to $\beta$-cyfluthrin was greater than $94 \%$ and for $\mathrm{AB} 1$ and AB2 strains it was 53 and 58\%, respectively (Fig. 3B). Mortality among the eight field strains ranged from 5 to $82 \%$, and the recovery on diet ranged from 18 to $90 \%$. Knockdown $(F=27.38$; $\mathrm{df}=8,36 ; P<0.0001)$ and mortality $(F=15.80 ; \mathrm{df}=8,35 ; P<0.0001)$ responses among $O$. surinamensis strains exposed to $\beta$-cyfluthrin were highly significant. Knockdown of AB1 and $\mathrm{AB} 2$ strains and mortality of $\mathrm{AB} 1, \mathrm{AB} 2$ and $\mathrm{MN}$ strains were significantly different from that of the laboratory strain $(P<0.05$; Dunnett's test).

$\beta$-cyfluthrin was extremely effective against the two R. dominica field strains and the laboratory strain with 98 to $100 \%$ knockdown and $100 \%$ mortality (Fig. 3C); similar responses were observed under room conditions.

Chlorpyrifos-methyl plus deltamethrin was more effective against $T$. castaneum field strains at constant conditions than at room conditions with 94 to $100 \%$ knockdown. The mortality ranged from 90 to $100 \%$ among the strains (Fig.3D). There were significant differences $(P<0.05)$ among field strains of $T$. castaneum exposed to chlorpyrifos-methyl plus deltamethrin in knockdown $(F=1.82 ; \mathrm{df}=16,68 ; P=0.047)$ and mortality $(F=3.93 ; \mathrm{df}=16,68 ; P<$ 0.0001). The knockdown and mortality of TP strain differed significantly from that of laboratory strain $(P<0.05$; Dunnett's test $)$.

The knockdown and mortality of the eight $O$. surinamensis field strains exposed to chlorpyrifos-methyl plus deltamethrin ranged from 77 to $92 \%$ and 67 to $98 \%$, respectively (Fig. 
3E). Knockdown $(F=2.41 ; \mathrm{df}=8,36 ; P=0.034)$ and mortality $(F=3.29 ; \mathrm{df}=8,36 ; P=$ 0.007) responses were highly significant among the strains. Dunnett's test showed that none of the strains was different in both knockdown and mortality from that of the laboratory strain. Chlorpyrifos-methyl plus deltamethrin produced higher knockdown (98 to 99\%) and mortality (38 to 40\%) in the two R. dominica field strains at constant than room conditions (Fig. 3F). The three strains of $R$. dominica exposed to chlorpyrifos-methyl plus deltamethrin differed significantly in mortality $(F=17.10 ; \mathrm{df}=2,12 ; P=0.0003)$, but not in knockdown $(F=0.51 ; \mathrm{df}$ $=2,12 ; P=0.614)$. Only mortality responses of both field strains were significantly different from that of the laboratory strain $(P<0.05$; Dunnett's test).

\subsection{Dose-response tests with $\beta$-cyfluthrin at constant conditions}

Exposing the three least susceptible strains of T. castaneum (CF, PD1, and TP) to up to four times the high rate of $\beta$-cyfluthrin resulted in 96 to $100 \%$ knockdown and 54 to $90 \%$ mortality (Table 5). The knockdown and mortality of the corresponding laboratory strain at all rates of $\beta$ cyfluthrin ranged from 96 to $100 \%$ and 72 to $90 \%$, respectively. Except for the mortality of TP strain which was different among the four $\beta$-cyfluthrin rates $(F=5.55 ; \mathrm{df}=3,16 ; P=0.008)$, the knockdown $(F$, range among strains $=0.76-2.67 ; \mathrm{df}=3,16 ; P=0.083-0.532)$ and mortality $(F$, range among strains $=0.91-2.11 ; \mathrm{df}=3,16 ; P=0.139-0.459)$ responses of all strains were similar among $\beta$-cyfluthrin rates. In the TP strain, there were no significant differences $(P>$ $0.05)$ in mortality at 0.04 to $0.08 \mathrm{~g}(\mathrm{AI}) \mathrm{m}^{-2}$ rates, but only mortality at rates of 0.04 and $0.08 \mathrm{~g}$ (AI) $\mathrm{m}^{-2}$ was significantly greater $(P<0.05)$ than mortality at $0.02 \mathrm{~g}(\mathrm{AI}) \mathrm{m}^{-2}$.

There was complete knockdown and mortality of the laboratory strain of $O$. surinamensis at all $\beta$-cyfluthrin rates (Table 5). The knockdown of field strains AB1 and AB2 among $\beta$ cyfluthrin rates was 71 to $100 \%$ while the mortality was 36 to $76 \%$. Knockdown responses of 
the strains differed significantly among $\beta$-cyfluthrin rates $(F$, range among strains $=3.87-4.63$; $\mathrm{df}=3,16 ; P=0.016-0.03)$, but mortality responses were not different among rates $(F$, range among strains $=1.22-2.62 ; \mathrm{df}=3,16 ; P=0.087-0.336)$. In strain $\mathrm{AB} 1$, knockdown at rates of 0.04 to $0.08 \mathrm{~g}(\mathrm{AI}) \mathrm{m}^{-2}$ was similar $(P>0.05)$ and knockdown at rates of 0.04 and $0.08 \mathrm{~g}(\mathrm{AI}) \mathrm{m}^{-2}$ was significantly greater $(P<0.05)$ than at $0.02 \mathrm{~g}(\mathrm{AI}) \mathrm{m}^{-2}$. In strain $\mathrm{AB} 2$, knockdown at rates of $0.04,0.06$ and $0.08 \mathrm{~g}(\mathrm{AI}) \mathrm{m}^{-2}$ was similar and significantly greater $(P<0.05)$ than at $0.02 \mathrm{~g}(\mathrm{AI})$ $\mathrm{m}^{-2}$.

\section{DISCUSSION}

Adults of field strains of T. castaneum and O. surinamensis were generally less susceptible to chlorpyrifos-methyl plus deltamethrin and $\beta$-cyfluthrin. Field strains of $R$. dominica showed reduced susceptibility to chlorpyrifos-methyl plus deltamethrin but not to $\beta$-cyfluthrin. Variation in susceptibility of different insect species and strains to insecticides could be due to the bioassay technique used, natural tolerance, and/or resistance. ${ }^{18}$ The use of two different bioassay methods, filter paper and treated grain assays, against same strains of $O$. surinamensis revealed that the resistance ratios for pyrethroids from both assays were not correlated. The probit regression slopes were 1.2 - 3 times higher for grain assays indicating greater susceptibility than

filter paper assays. ${ }^{24}$ Field strains of the granary weevil, Sitophilus granarius (L.), from different locations in the former Yugoslavia were 0.5 to 30 times less susceptible to the organophosphates dichlorvos, malathion, chlorpyrifos-methyl, and pirimiphos-methyl, and to the pyrethroids deltamethrin and cypermethrin than the laboratory strain based on discriminating-dose tests with treated filter papers. ${ }^{16}$ 
Adults of four field strains of $O$. surinamensis collected from stored barley on Minnesota farms showed 8 to $40 \%$ mortality when exposed to chlorpyrifos-methyl at a discriminating dose of $0.09 \mathrm{mg} / 7 \mathrm{~cm}$ diameter filter paper disc $\left(38.5 \mathrm{~cm}^{2}\right)$ compared with a laboratory strain which showed $100 \%$ mortality even before the insecticide was registered for use on this commodity, indicating natural tolerance ${ }^{17}$ The wild strains of O. surinamensis in Australia showed low resistance levels ( $<10$-fold) to chlorpyrifos-methyl in treated filter-paper assays. ${ }^{25}$ Strains of $R$. dominica from Brazil were found to be 2 to 874 times more resistant to deltamethrin than a susceptible laboratory strain. ${ }^{26}$ Resistance to chlorpyrifos-methyl was detected in R. dominica strains collected from Brazil and Kansas, USA, with resistance ratios at the median lethal concentration $\left(\mathrm{LC}_{50}\right)$ ranging from 5.6 to $167.9 .{ }^{27} \mathrm{~A}$ low level of resistance (1.2 to 1.8 -fold) was observed to deltamethrin in 11 field strains of the maize weevil, Sitophilus zeamais Motschulsky, collected from nine states in Mexico. ${ }^{28}$

In Australia, resistance to cyfluthrin has been reported in $O$. surinamensis ${ }^{24}$ and $T$. castaneum ${ }^{29}$ using filter paper and grain assays. Resistance to cyfluthrin was also reported in other insect species such as the housefly, Musca domestica L.; ${ }^{30}$ German cockroach, Blattella germanica (L.); ${ }^{31,32}$ beet armyworm, Spodoptera exigua (Hübner), ${ }^{33}$ and lesser meal worm, Alphitobius diaperinus (Panzer) $\cdot{ }^{34}$ In the present study, R. dominica showed reduced susceptibility to chlorpyrifos-methyl plus deltamethrin. Some previous studies have reported the field strains of $R$. dominica to be resistant to chlorpyrifos-methyl ${ }^{27,35,36}$ and to deltamethrin ${ }^{26}$ but not to the binary mixture. Chlorpyrifos-methyl at $3.0 \mathrm{mg}(\mathrm{AI}) \mathrm{kg}^{-1}$ of grain was effective against T. castaneum and O. surinamensis on stored wheat but not against $R$. dominica. ${ }^{37}$

The results on insect susceptibility to the tested insecticides on concrete surfaces are at variance from that observed with the same insecticides on stored grain. For example, on stored 
rice and wheat, chlorpyrifos-methyl plus deltamethrin was effective against the psocids Lepinotus reticulatus Enderlein, Liposcelis entomophila (Enderlein), Liposcelis bostrychophila Badonnel, and Liposcelis paeta Pearman. ${ }^{12}$ It was also effective at the labeled rate against adults of R. dominica, S. oryzae, and T. castaneum on wheat and R. dominica and S. oryzae adults on short-grain and long-grain rices. ${ }^{13}$ The reduced susceptibility of adults of T. castaneum and $O$. surinamensis strains to chlorpyrifos-methyl plus deltamethrin and $\beta$-cyfluthrin on concrete surfaces as opposed to grain could be due to absorption or loss of the sprayed solution into the porous concrete. The concrete surface is also alkaline $(\mathrm{pH} \sim 10.5)$ and may have hydrolyzed the insecticide. ${ }^{38}$ The persistence of cyfluthrin can be increased by sealing concrete with various commercial sealants. ${ }^{2}$ An additional factor reducing the efficacy of insecticides on concrete may be uneven spray deposition during application, leading to areas with little or no insecticide deposit. Insects seeking such areas may not receive a lethal dose of the insecticide.

On grain, both contact and ingestion toxicity are important, whereas on concrete there is only contact toxicity. On grain, insects are typically exposed for $1 \mathrm{wk}$ or more, but on concrete surfaces the maximum exposure time in our study was $24 \mathrm{~h}$. Such short exposures may have been sublethal ${ }^{39}$ and allowed insect recovery when placed on diets. The exposure of $R$. dominica adults for $24 \mathrm{~h}$ or less on wheat treated with an emulsifiable concentrate of cyfluthrin at 1,2, and $4 \mathrm{mg}(\mathrm{AI}) \mathrm{kg}^{-1}$ gave less than $90 \%$ mortality. ${ }^{40}$

The poor effectiveness of $\beta$-cyfluthrin against $T$. castaneum field strains at 0.02 to 0.08 $\mathrm{g}(\mathrm{AI}) \mathrm{m}^{-2}$ rate in this study is in contrast to excellent control shown by cyfluthrin wettable powder at $0.04 \mathrm{~g}(\mathrm{AI}) \mathrm{m}^{-2}$ against a laboratory strain of $T$. castaneum. ${ }^{3}$ The wettable powder formulation gave $90 \%$ mortality of $T$. castaneum adults when exposed for 0.5 to $4.0 \mathrm{~h}$ on deposits aged for 8 to $24 \mathrm{wk}^{3}$ Similar data on O. surinamensis with a wettable powder 
formulation are not available for comparisons. $\beta$-cyfluthrin, an enriched isomeric form of the two biologically active diastereoisomeric pairs of isomers of cyfluthrin, should perform better or as well as the wettable powder formulation. For example, $\beta$-cyfluthrin showed high short-term efficacy with time to $95 \%$ mortality ( $\mathrm{LT}_{95}$ ) of 12 to $15 \mathrm{~h}$ against stored-product psocids, $L$. bostrychophila and L. entomophila, when applied at a low rate of $0.002 \mathrm{~g}(\mathrm{AI}) \mathrm{m}^{-2}$ on concrete. ${ }^{11}$ Kaufman and Rutz ${ }^{41}$ reported the wettable powder formulation of cyfluthrin to be more toxic than the suspension concentrate formulation when applied to painted and unpainted plywood panels against M. domestica collected from dairies in the State of New York.

Except for R. dominica strains exposed to $\beta$-cyfluthrin, in our study percentage mortality of $T$. castaneum and $O$. surinamensis strains was generally lower than knockdown indicating recovery when placed on diets. Recovery of insects on food after a brief insecticide exposure may be due to absorption of insecticide from the insect's integument by the food particles, or an increase in insect's ability to detoxify the insecticide after removal from treated substrates. ${ }^{9}$ The time for $90 \%$ mortality of beetles $\left(\mathrm{LT}_{90}\right)$ placed on wheat flour for $1 \mathrm{wk}$ after exposure to 0.02 $\mathrm{g}(\mathrm{AI}) \mathrm{m}^{-2}$ of cyfluthrin wettable powder for 0.5 to $2.0 \mathrm{~h}$ was $195 \mathrm{~min}$, whereas $\mathrm{LT}_{90}$ for those without flour was $19 \mathrm{~min} .{ }^{4}$ The presence of wheat flour on methoprene-treated concrete surfaces reduced the efficacy of methoprene against $T$. castaneum larvae (10 to $12 \mathrm{~d}$ old after eclosing from eggs). ${ }^{42}$ Therefore, sanitation of empty storage surfaces is very important to improve effectiveness of residual insecticides. The fact that there is recovery indicates that the insecticides did not exhibit any delayed effects. Delayed mortality effects have been reported in R. dominica ${ }^{43,44}$ but not in S. oryzae after short exposures to spinosad-treated wheat. ${ }^{44}$

In the present study, $\beta$-cyfluthrin was found to be more effective at the room temperature of $24-25^{\circ} \mathrm{C}$ than at $28^{\circ} \mathrm{C}$ against $T$. castaneum and $O$. surinamensis. These strains and those of $R$. 
dominica were more susceptible at $28^{\circ} \mathrm{C}$ than at $25^{\circ} \mathrm{C}$ when exposed to chlorpyrifos-methyl plus deltamethrin. In tests at $20,25,30$, and $35^{\circ} \mathrm{C}$, cyfluthrin toxicity was negatively correlated with temperature in tests with adults of T. castaneum, ${ }^{10}$ T. confusum, the larger grain borer, Prostephanus truncatus (Horn) and larvae of P. interpunctella and the almond moth, Cadra cautella (Walker) ${ }^{45}$. Cyfluthrin toxicity was unaffected by temperature in tests with $R$. dominica adults. ${ }^{45}$ Organophosphate insecticides such as chlorpyrifos-methyl were more toxic at higher $\left(25^{\circ} \mathrm{C}\right)$ than lower $\left(17.5\right.$ and $\left.10^{\circ} \mathrm{C}\right)$ temperatures against adults of $O$. surinamensis, ${ }^{46} \mathrm{~T}$. castaneum, and S. granarius. ${ }^{47}$ A positive correlation was found between temperature and effectiveness of organophosphate insecticides such as malathion, pirimiphos-methyl, and fenitrothion against adults of T. confusum. ${ }^{48}$ Deltamethrin displayed a negative temperature coefficient (more toxic at 15.6 than at $37.8^{\circ} \mathrm{C}$ ) against the third instar larvae of cabbage looper, Trichoplusia ni (Hubner), and adults of the boll weevil, Anthonomus grandis grandis Boheman, but exhibited either a neutral or a positive temperature coefficient against third instar larvae of the fall armyworm, Spodoptera frugiperda (J. E. Smith), and tobacco budworm, Heliothis virescens (F.). ${ }^{49,50}$ An overall negative temperature coefficient was observed for deltamethrin emulsifiable concentrate formulation when tested against $2^{\text {nd }}$ instar nymphs of the grasshopper Melanoplus spp. at 15.6 to $37.8^{\circ} \mathrm{C}$, with a slight positive temperature coefficient at 21.1 to $26.7^{\circ} \mathrm{C} .^{51}$ However, a neutral or positive temperature coefficient was reported with a flowable formulation of deltamethrin when tested at 15 to $31^{\circ} \mathrm{C}$ against Melanoplus spp. ${ }^{52}$ Based on these studies we hypothesize that deltamethrin in the combination product may have exhibited either neutral or positive temperature coefficient.

Our results show that $\beta$-cyfluthrin is an ideal insecticide to use in clean, empty bin floors prior to storing wheat only to control $R$. dominica adults but not $T$. castaneum and $O$. 
surinamensis strains. The reduced susceptibility of field and laboratory strains of the latter two species may be due to an inherent formulation deficiency or resistance, since four times the labeled rate failed to provide complete control. Chlorpyrifos-methyl plus deltamethrin was only partially effective against strains of all three species. There is documented evidence of resistance in field strains of these three species to one or both active ingredients. This is the first report that characterized susceptibility, or lack thereof, of field strains of three insect species from Kansas and other parts of the United States to two approved insecticides used for empty-bin treatments. According to surveys of wheat stored on-farm and elevators in Kansas, the most common insect species associated with stored wheat are $R$. dominica, S.oryzae, and T. castaneum. In addition, Oryzaephilus spp. and Cryptolestes spp. are also found in stored grain in Kansas. ${ }^{53,54}$ Based on our results, no single insecticide can be recommended to provide adequate control of all species tested. More work is needed on the mechanism of detoxification of these chemicals by the three species to understand why some chemicals are effective against some species and strains and not against others. Evaluation of other recommended empty-bin insecticides with the field strains is also needed to identify a broad-spectrum insecticide that is effective against species commonly found in empty bins. 


\section{ACKNOWLEDGEMENTS}

Bayer CropScience (Research Triangle Park, NC, USA) provided the insecticides and financial support for this research. The authors are grateful to Kansas producers for permitting us to sample their stored grain to collect field strains, and to Dr. James Campbell, USDA-ARS, Center for Grain and Animal Health Research, Manhattan, KS, USA, for providing five T. castaneum and one R. dominica field strains. Dr. Nickolas Kavallieratos reviewed an earlier version of the manuscript. Mention of trade names or commercial products in this publication is solely for the purpose of providing specific information and does not imply recommendation or endorsement by the U.S. Department of Agriculture (USDA) or by Kansas State University. USDA is an equal opportunity provider and employer. This paper is contribution number $13-214-\mathrm{J}$ of the Kansas State University Agricultural Experiment Station. 


\section{REFERENCES}

1. Reed C and Pedersen J, Farm-stored wheat in Kansas - facilities, conditions, pest-control, and cost comparisons. Kans Agric Expt Station Bull 652:1-32 (1987).

2. Arthur FH, Residual efficacy of cyfluthrin emulsifiable concentrate and wettable powder formulations on porous concrete and on concrete sealed with commercial products prior to insecticide application. J Stored Prod Res 30:79-86 (1994).

3. Arthur FH, Residual studies with cyfluthrin wettable powder: Toxicity toward red flour beetles (Coleoptera : Tenebrionidae) exposed for short intervals on treated concrete. $J$ Econ Entomol 91:309-319 (1998).

4. Arthur FH, Effects of a food source on red flour beetle (Coleoptera : Tenebrionidae) survival after exposure on concrete treated with cyfluthrin. J Econ Entomol 91:773-778 (1998).

5. Arthur FH, Survival of red flour beetles (Coleoptera : Tenebrionidae) on concrete partially treated with cyfluthrin. J Econ Entomol 92:981-987 (1999).

6. Arthur FH, Residual susceptibility of fifth instar Plodia interpunctella to cyfluthrin wettable powder. J Stored Prod Res 35:99-105 (1999).

7. Parkin EA, Relative toxicity and persistence of insecticides applied as water-dispersible powders against stored-product beetles. Annals Appl Biol 57:1-4 (1966).

8. Arthur FH, Cyfluthrin WP and EC formulations to control malathion-resistant red flour beetles and confused flour beetles (Coleoptera, Tenebrionidae) - effects of paint on residual efficacy. J Entomol Sci 27:436-444 (1992).

9. Arthur FH, Impact of accumulated food on survival of Tribolium castaneum on concrete treated with cyfluthrin wettable powder. J Stored Prod Res 36:15-23 (2000). 
10. Arthur FH, Effect of temperature on residual toxicity of cyfluthrin wettable powder. $J$ Econ Entomol 92:695-699 (1999).

11. Guedes RNC, Campbell JF, Arthur FH, Opit GP, Zhu KY and Throne JE, Acute lethal and behavioral sublethal responses of two stored-product psocids to surface insecticides. Pest Manag Sci 64:1314-1322 (2008).

12. Athanassiou CG, Arthur FH and Throne JE, Efficacy of grain protectants against four psocid species on maize, rice and wheat. Pest Manag Sci 65:1140-1146 (2009).

13. Subramanyam Bh, Hartzer M and Boina DR, Performance of pre-commercial release formulations of spinosad against five stored-product insect species on four stored commodities. J Pest Sci 85:331- 339 (2012).

14. Athanassiou CG, Kavallieratos NG and Chintzoglou GJ, Effectiveness of spinosad dust against different European populations of the confused flour beetle, Tribolium confusum Jacquelin du Val. J Stored Prod Res 44:47-51 (2008).

15. Huang F, Subramanyam Bh and Toews MD, Susceptibility of laboratory and field strains of four stored-product insect species to spinosad. J Econ Entomol 97: 2154-2159 (2004).

16. Kljajic P and Peric I, Susceptibility to contact insecticides of granary weevil Sitophilus granarius (L.) (Coleoptera : Curculionidae) originating from different locations in the former Yugoslavia. J Stored Prod Res 42:149-161(2006).

17. Subramanyam Bh, Harein PK and Cutkomp LK, Organo-phosphate resistance in adults of red flour beetle (Coleoptera, Tenebrionidae) and sawtoothed grain beetle (Coleoptera, Cucujidae) infesting barley stored on farms in Minnesota. J Econ Entomol 82:989-995 (1989). 
18. Subramanyam Bh and Hagstrum DW, Integrated management of insects in stored products, Marcel Dekker, Boston, MA, USA, (1996).

19. Subramanyam Bh, Hagstrum DW and Schenk TC, Sampling adult beetles (Coleoptera) associated with stored grain: comparing detection and mean trap catch efficiency of two types of probe traps. Environ Entomol 22:33-42 (1993).

20. SAS Institute Inc. SAS/STAT ${ }^{\circledR} 9.2$ User's Guide. Cary, NC, USA (2008).

21. Draper NR and Smith H, Applied regression-analysis. 3rd Edition, John Wiley and Sons, Inc., NY, USA, (1981).

22. Abbott WS, A method of computing the effectiveness of an insecticide. J Econ Entomol 18:65-267 (1925).

23. Zar JH, Biostatistical analysis, 2nd ed. Prentice Hall, Englewood Cliffs, NJ, USA (1984).

24. Collins PJ and Wilson D, Efficacy of current and potential grain protectant insecticides against a fenitrothion-resistant strain of the sawtoothed grain beetle, Oryzaephilus surinamensis L. Pestic Sci 20:93-104 (1987).

25. Attia FI and Frecker T, Cross-resistance spectrum and synergism studies in organophosphorus-resistant strains of Oryzaephilus surinamensis (Coleoptera, Cucujidae) in Australia. J Econ Entomol 77:1367-1370 (1984).

26. Lorini I and Galley DJ, Deltamethrin resistance in Rhyzopertha dominica (F.) (Coleoptera : Bostrichidae), a pest of stored grain in Brazil. J Stored Prod Res 35:37-45 (1999).

27. Guedes RNC, Dover BA and Kambhampati S, Resistance to chlorpyrifos-methyl, pirimiphos-methyl, and malathion in Brazilian and US populations of Rhyzopertha dominica (Coleoptera: Bostrichidae). J Econ Entomol 89:27-32 (1996). 
28. Perez-Mendoza J, Survey of insecticide resistance in Mexican populations of maize weevil, Sitophilus zeamais Motschulsky (Coleoptera: Curculionidae). J Stored Prod Res 35:107-115 (1999).

29. Collins PJ, A new resistance to pyrethroids in Tribolium castaneum (Herbst). Pestic Sci 28:101-115 (1990).

30. Kaufman PE, Scott JG and Rutz DA, Monitoring insecticide resistance in house flies (Diptera : Muscidae) from New York dairies. Pest Manag Sci 57:514-521 (2001).

31. Cochran DG, Monitoring for insecticide resistance in field-collected strains of the German-cockroach (Dictyoptera, Blattellidae). J Econ Entomol 82:336-341 (1989).

32. Chai R-Y and Lee C-Y, Insecticide resistance profiles and synergism in field populations of the German cockroach (Dictyoptera: Blattellidae) from Singapore. J Econ Entomol 103:460-471 (2010).

33. Aldosari SA, Watson TF, Sivasupramaniam S and Osman AA, Susceptibility of field populations of beet armyworm (Lepidoptera: Noctuidae) to cyfluthrin, methomyl, and profenofos, and selection for resistance to cyfluthrin. J Econ Entomol 89:1359-1363 (1996).

34. Hamm RL, Kaufman PE, Reasor CA, Rutz DA and Scott JG, Resistance to cyfluthrin and tetrachlorvinphos in the lesser mealworm, Alphitobius diaperinus, collected from the eastern United States. Pest Manag Sci 62:673-677 (2006).

35. Beeman RW and Wright VF, Monitoring for resistance to chlorpyrifos-methyl, pirimiphos-methyl and malathion in Kansas populations of stored-product insects. $J$ Kans Entomol Soc 63:385-392 (1990).

36. Zettler JL and Cuperus GW, Pesticide resistance in Tribolium castaneum (Coleoptera, 
Tenebrionidae) and Rhyzopertha dominica (Coleoptera, Bostrichidae) in wheat. J Econ Entomol 83:1677-1681 (1990).

37. Subramanyam Bh, Toews MD, Ileleji KE, Maier DE, Thompson GD and Pitts TJ, Evaluation of spinosad as a grain protectant on three Kansas farms. Crop Prot 26:10211030 (2007).

38. White NDG and Leesch JG, Chemical control, pp. 287 - 330. In Subramanyam B and Hagstrum DW(eds.), Integrated management of insects in stored products, Marcel Dekker, Boston, MA, USA (1996).

39. Guedes RNC, Guedes NMP and Rosi-Denadai CA, Sub-lethal effects of insecticides on stored-product insects: current knowledge and future needs. Stewart Postharvest Rev 7:15 (2011).

40. Arthur FH, Knockdown, mortality, and progeny production of lesser grain borers (Coleoptera : Bostrichidae) and rice weevils (Coleoptera : Curculionidae) exposed for short intervals on wheat treated with cyfluthrin. J Econ Entomol 92:1198-1205 (1999).

41. Kaufman PE and Rutz DA, Susceptibility of house flies (Diptera : Muscidae) exposed to commercial insecticides on painted and unpainted plywood panels. Pest Manag Sci 58:174-178 (2002).

42. Wijayaratne LKW, Fields PG and Arthur FH, Residual efficacy of methoprene for control of Tribolium castaneum (Coleoptera: Tenebrionidae) larvae at different temperatures on varnished wood, concrete, and wheat. J Econ Entomol 105:718-725 (2012).

43. Boina DR, Subramanyam Bh and Mutambuki K, Delayed mortality responses of Rhyzopertha dominica (F.) adults subjected to short exposures on spinosad-treated wheat. 
J Stored Prod Res 48:149-152 (2012).

44. Getchell AI and Subramanyam B, Immediate and delayed mortality of Rhyzopertha dominica (Coleoptera: Bostrichidae) and Sitophilus oryzae (Coleoptera: Curculionidae) adults exposed to spinosad-treated commodities. J Econ Entomol 101:1022-1027 (2008).

45. Subramanyam Bh and Cutkomp LK, Influence of posttreatment temperature on toxicity of pyrethroids to 5 species of stored-product insects. J Econ Entomol 80:9-13 (1987).

46. Barson $\mathrm{G}$, The effects of temperature and humidity on the toxicity of 3 organophosphorus insecticides to adult Oryzaephilus surinamensis (L). Pestic Sci 14:145-152 (1983).

47. Tyler PS and Binns TJ, The influence of temperature on the susceptibility to 8organophosphorus insecticides of susceptible and resistant strains of Tribolium castaneum, Oryzaephilus surinamensis and Sitophilus granarius. J Stored Prod Res 18:13-19 (1982).

48. O'Donnell MJ, The toxicities of four insecticides to Tribolium confusum Duv in two sets of conditions of temperature and humidity. J Stored Prod Res 16:71-74 (1980).

49. Sparks TC, Shour MH and Wellemeyer EG, Temperature-toxicity relationships of pyrethroids on three Lepidopterans. J Econ Entomol 75:643-646 (1982).

50. Sparks TC, Pavloff AM, Rose RL and Clower DF, Temperature-toxicity relationships of pyrethroids on Heliothis virescens (F) (Lepidoptera, Noctuidae) and Anthonomus grandis grandis Boheman (Coleoptera, Curculionidae). J Econ Entomol 76:243-246 (1983).

51. Hinks CF, The influence of temperature on the efficacy of 3 pyrethroid insecticides against the grasshopper, Melanoplus sanguinipes (Fab) (Orthoptera, Acrididae), under laboratory conditions. Can Entomol 117:1007-1012 (1985). 
52. Johnson DL, Influence of temperature on toxicity of 2 pyrethroids to grasshoppers (Orthoptera, Acrididae). J Econ Entomol 83:366-373 (1990).

53. Reed CR, Wright VF, Mize TW, Pedersen JR and Evans JB, Pitfall traps and grain samples as indicators of insects in farm-stored wheat. J Econ Entomol 84:1381-1387 (1991).

54. Reed CR, Hagstrum DW, Flinn PW and Allen RF, Wheat in bins and discharge spouts, and grain residues on floors of empty bins in concrete grain elevators as habitats for stored-grain beetles and their natural enemies. J Econ Entomol 96:996-1004 (2003). 
Table 1. Sites and year of collection of adult T. castaneum, O. surinamensis, and R. dominica field strains

\begin{tabular}{|c|c|c|c|c|c|}
\hline Species & Strain ID & County, State & Location & Commodity & Collection year \\
\hline \multirow[t]{16}{*}{ T. castaneum } & AB1 & Dickinson, KS & Abilene & Wheat & 2011 \\
\hline & AB2 & Dickinson, KS & Abilene & Wheat & 2011 \\
\hline & $\mathrm{AZ}$ & Maricopa, $\mathrm{AZ}^{\mathrm{a}}$ & $\mathrm{b}^{\mathrm{b}}$ & Flour mill & 2009 \\
\hline & $\mathrm{CF}$ & Washington, KS & Clifton & Wheat & 2011 \\
\hline & $\mathrm{CN}$ & McPherson, KS & Canton & Wheat & 2011 \\
\hline & $\mathrm{GH}$ & Russell, KS & Gorham & Wheat & 2011 \\
\hline & $\mathrm{HN}$ & Stafford, $\mathrm{KS}^{\mathrm{a}}$ & 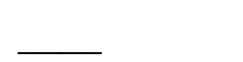 & Flour mill & 2001 \\
\hline & $\mathrm{IL}$ & Cook, $\mathrm{IL}^{\mathrm{c}}$ & Bridgeview & Rice facility & 2011 \\
\hline & $\mathrm{KC}$ & Jackson, $\mathrm{MO}^{\mathrm{a}}$ & 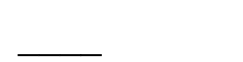 & Flour mill & 2005 \\
\hline & MN1 & Ottawa, KS & Minneapolis & Wheat & 2011 \\
\hline & MN2 & Ottawa, KS & Minneapolis & Wheat & 2011 \\
\hline & PD1 & Russell, KS & Paradise & Wheat & 2011 \\
\hline & PD2 & Russell, KS & Paradise & Corn & 2011 \\
\hline & $\mathrm{PO}$ & $\mathrm{KS}^{\mathrm{a}}$ & $\ldots$ & Flour mill & 2001 \\
\hline & SR & Dickinson, $\mathrm{KS}^{\mathrm{a}}$ & 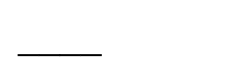 & Flour mill & 2001 \\
\hline & TP & Mitchell, KS & Tipton & Wheat & 2011 \\
\hline \multirow[t]{4}{*}{ O. surinamensis } & $\mathrm{AB} 1$ & Dickinson, KS & Abilene & Wheat & 2011 \\
\hline & AB2 & Dickinson, KS & Abilene & Wheat & 2011 \\
\hline & $\mathrm{CF}$ & Washington, KS & Clifton & Wheat & 2011 \\
\hline & $\mathrm{CN}$ & McPherson, KS & Canton & Wheat & 2011 \\
\hline
\end{tabular}




\begin{tabular}{|c|c|c|c|c|c|}
\hline & MN1 & Ottawa, KS & Minneapolis & Wheat & 2011 \\
\hline & PD1 & Russell, KS & Paradise & Wheat & 2011 \\
\hline & PD2 & Russell, KS & Paradise & Corn & 2011 \\
\hline & $\mathrm{TP}$ & Mitchell, KS & Tipton & Wheat & 2011 \\
\hline R. dominica & $\mathrm{CF}$ & Washington, KS & Clifton & Wheat & 2011 \\
\hline & RL & Riley, $\mathrm{KS}^{\mathrm{a}}$ & & Flour mill & 2007 \\
\hline
\end{tabular}

${ }^{\mathrm{a}}$ These strains were collected prior to 2011 and were provided by Dr. James Campbell, USDAARS, Center for Grain and Animal Health Research, Manhattan, KS, USA.

${ }^{b}$ Exact city name is not disclosed at the request of the mill manager.

${ }^{\mathrm{c}}$ Strain collected by one of the authors (Bhadriraju Subramanyam) during a visit to a riceprocessing facility in 2011. 
Table 2. Parameter estimates for regression models fit to knockdown and mortality data of the laboratory strains of three insect species exposed to insecticide deposits on concrete

\begin{tabular}{|c|c|c|c|c|c|c|}
\hline \multirow[t]{2}{*}{ Species } & \multirow[t]{2}{*}{ Insecticide } & \multirow[t]{2}{*}{ Response } & \multirow[t]{2}{*}{$n$} & \multicolumn{2}{|c|}{ Mean \pm SE for parameters ${ }^{\mathrm{a}}$} & \multirow[t]{2}{*}{$r^{2}$} \\
\hline & & & & $a$ & $b$ & \\
\hline \multirow[t]{6}{*}{ T. castaneum } & $\beta$-cyfluthrin low rate & Knockdown & 8 & $99.5 \pm 1.1$ & $-78.9 \pm 3.0$ & 0.99 \\
\hline & & Mortality $^{\mathrm{b}}$ & 6 & $22.3 \pm 7.8$ & $3.2 \pm 0.8$ & 0.81 \\
\hline & $\beta$-cyfluthrin high rate & Knockdown & 8 & $99.6 \pm 1.7$ & $-54.7 \pm 4.6$ & 0.96 \\
\hline & & Mortality $^{\mathrm{b}}$ & 8 & $21.6 \pm 5.1$ & $2.4 \pm 0.4$ & 0.87 \\
\hline & Chlorpyrifos-methyl & Knockdown & 8 & $102.8 \pm 2.2$ & $-86.4 \pm 6.1$ & 0.97 \\
\hline & plus deltamethrin & Mortality & 8 & $99.6 \pm 0.9$ & $-84.1 \pm 2.4$ & 0.99 \\
\hline \multirow[t]{6}{*}{ O. surinamensis } & $\beta$-cyfluthrin low rate & Knockdown & & $-^{c}$ & - & \\
\hline & & Mortality & 6 & $91.0 \pm 2.4$ & $-23.9 \pm 5.9$ & 0.80 \\
\hline & $\beta$-cyfluthrin high rate & Knockdown & & - & - & \\
\hline & & Mortality & 5 & $101.5 \pm 1.7$ & $-1655.8 \pm 211.6$ & 0.95 \\
\hline & Chlorpyrifos-methyl & Knockdown & 8 & $100.0 \pm 0.2$ & $-39.6 \pm 0.6$ & 0.99 \\
\hline & plus deltamethrin & Mortality & 8 & $98.2 \pm 3.7$ & $-56.8 \pm 10.1$ & 0.84 \\
\hline \multirow[t]{6}{*}{ R. dominica } & $\beta$-cyfluthrin low rate & Knockdown & 8 & $100.4 \pm 0.4$ & $-9.9 \pm 1.0$ & 0.94 \\
\hline & & Mortality & & - & - & \\
\hline & $\beta$-cyfluthrin high rate & Knockdown & 8 & $100.4 \pm 0.4$ & $-9.6 \pm 1.0$ & 0.94 \\
\hline & & Mortality & & - & - & \\
\hline & Chlorpyrifos-methyl & Knockdown & 8 & $103.1 \pm 2.6$ & $-82.8 \pm 7.1$ & 0.96 \\
\hline & plus deltamethrin & Mortality & 8 & $89.4 \pm 5.8$ & $-87.6 \pm 15.9$ & 0.83 \\
\hline
\end{tabular}


${ }^{a}$ All regression ANOVA values were significant indicating that the slope $(b)$ is not equal to zero $(F$, range among species, insecticides, and responses $=17.32-1232.66 ; \mathrm{df}=1,6$ except for $T$. castaneum and $O$. surinamensis mortality with $\beta$-cyfluthrin at low rate where $\mathrm{df}=1,4$; and $O$. surinamensis mortality with $\beta$-cyfluthrin at high rate where $\mathrm{df}=1,3 ; P \leq 0.016$ ).

${ }^{\mathrm{b}}$ Linear equation $y=a+b x$ was fit to the data; all other responses were fit to the nonlinear equation $y=a+b / x^{2}$.

${ }^{\mathrm{c} K n o c k d o w n}$ or mortality at all observation times was $100 \%$. 
Table 3. Comparison of knockdown or mortality responses of three insect species between insecticides and rates

\begin{tabular}{|c|c|c|c|c|c|}
\hline Species & Response & Insecticides compared & $F$-value & $\mathrm{df}$ & $P$-value ${ }^{\mathrm{a}}$ \\
\hline \multirow[t]{5}{*}{ T. castaneum } & Knockdown & $\begin{array}{l}\beta \text {-cyfluthrin high rate vs } \beta \text {-cyfluthrin } \\
\text { low rate }\end{array}$ & 12.16 & 2,12 & 0.001 \\
\hline & & $\begin{array}{l}\beta \text {-cyfluthrin low rate vs Chlorpyrifos- } \\
\text { methyl plus deltamethrin }\end{array}$ & 1.05 & 2,12 & 0.380 \\
\hline & & $\beta$-cyfluthrin high rate vs & 8.81 & 2,12 & 0.004 \\
\hline & & $\begin{array}{l}\text { Chlorpyrifos-methyl plus } \\
\text { deltamethrin }\end{array}$ & & & \\
\hline & Mortality & $\begin{array}{l}\beta \text {-cyfluthrin low rate vs } \beta \text {-cyfluthrin } \\
\text { high rate }\end{array}$ & 1.52 & 2,10 & 0.266 \\
\hline \multirow[t]{3}{*}{ O. surinamensis } & Mortality & $\begin{array}{l}\beta \text {-cyfluthrin high rate vs } \beta \text {-cyfluthrin } \\
\text { low rate }\end{array}$ & 9.18 & 2,7 & 0.011 \\
\hline & & $\begin{array}{l}\beta \text {-cyfluthrin low rate vs Chlorpyrifos- } \\
\text { methyl plus deltamethrin }\end{array}$ & 3.59 & 2,10 & 0.067 \\
\hline & & $\begin{array}{l}\beta \text {-cyfluthrin high rate vs } \\
\text { Chlorpyrifos-methyl plus } \\
\text { deltamethrin }\end{array}$ & 3.77 & 2,9 & 0.065 \\
\hline \multirow[t]{2}{*}{ R. dominica } & Knockdown & $\begin{array}{l}\beta \text {-cyfluthrin low rate vs } \beta \text {-cyfluthrin } \\
\text { high rate }\end{array}$ & 0.03 & 2,12 & 0.971 \\
\hline & & $\begin{array}{l}\beta \text {-cyfluthrin low rate vs Chlorpyrifos- } \\
\text { methyl plus deltamethrin }\end{array}$ & 59.83 & 2,12 & $<0.001$ \\
\hline
\end{tabular}




\section{Chlorpyrifos-methyl plus}

deltamethrin

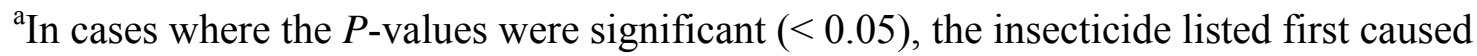
significantly greater knockdown and/or mortality than the other in the pair being compared.

Some insecticide combinations were not compared because of $100 \%$ knockdown or mortality at all observation times. 
Table 4. Comparison of knockdown or mortality responses between insect species by insecticides and rate

\begin{tabular}{|c|c|c|c|c|c|}
\hline Insecticide & Response & Species compared & $F$-value & $\mathrm{df}$ & $P$-value ${ }^{\mathrm{a}}$ \\
\hline Cyfluthrin low rate & Knockdown & R. dominica vs T. castaneum & 307.95 & 2,12 & $<0.0001$ \\
\hline Cyfluthrin high rate & Knockdown & R. dominica vs $T$. castaneum & 60.44 & 2,12 & $<0.0001$ \\
\hline Chlorpyrifos-methyl & Knockdown & T. castaneum vs $R$. dominica & 0.11 & 2,12 & 0.895 \\
\hline \multirow[t]{5}{*}{ plus deltamethrin } & & O. surinamensis vs $T$. castaneum & 31.90 & 2,12 & $<0.001$ \\
\hline & & O.surinamensis vs $R$. dominica & 19.87 & 2,12 & 0.0001 \\
\hline & Mortality & T. castaneum vs $R$. dominica & 2.15 & 2,12 & 0.159 \\
\hline & & T. castaneum vs $O$. surinamensis & 3.87 & 2,12 & 0.050 \\
\hline & & O. surinamensis vs $R$. dominica & 3.91 & 2,12 & 0.049 \\
\hline
\end{tabular}

${ }^{\mathrm{a}}$ In cases where the $P$-values were significant $(<0.05)$, the insect species listed first showed significantly greater knockdown and/or mortality than the other in the pair being compared. 
Table 5. Knockdown and mortality of laboratory and select least susceptible field strains of T. castaneum and O. surinamensis exposed to concrete surfaces treated at or above the high labeled rate of $\beta$-cyfluthrin ${ }^{\mathrm{a}, \mathrm{b}}$

\begin{tabular}{|c|c|c|c|c|c|c|c|c|}
\hline \multirow{2}{*}{ Strain } & \multicolumn{4}{|c|}{ Mean \pm SE knockdown $(\%)$ at $\beta$-cyfluthrin rate $\left(\mathrm{g}[\mathrm{AI}] \mathrm{m}^{-2}\right)$ of: } & \multicolumn{4}{|c|}{ Mean \pm SE mortality $(\%)$ at $\beta$-cyfluthrin rate $\left(\mathrm{g}[\mathrm{AI}] \mathrm{m}^{-2}\right)$ of: } \\
\hline & 0.02 & 0.04 & 0.06 & 0.08 & 0.02 & 0.04 & 0.06 & 0.08 \\
\hline Lab. & $96.0 \pm 2.4^{\mathrm{c}}$ & 100 & $98.0 \pm 2.0$ & $98.0 \pm 2.0$ & $72.0 \pm 10.7^{\mathrm{d}}$ & $74.0 \pm 5.1$ & $84.0 \pm 10.3$ & $90.0 \pm 7.7$ \\
\hline PD1 & $98.0 \pm 2.0^{\mathrm{c}}$ & 100 & 100 & 100 & $66.0 \pm 12.5^{\mathrm{d}}$ & $90.0 \pm 7.7$ & $72.0 \pm 7.3$ & $78.0 \pm 4.9$ \\
\hline $\mathrm{TP}$ & $96.0 \pm 2.4^{\mathrm{c}}$ & 100 & 100 & 100 & $54.0 \pm 9.3 b$ & $82.2 \pm 5.0 \mathrm{a}$ & $74.7 \pm 7.1 \mathrm{ab}$ & $90.0 \pm 3.2 \mathrm{a}$ \\
\hline \multicolumn{9}{|c|}{ O. surinamensis } \\
\hline $\mathrm{AB} 2$ & $80.0 \pm 8.4 b$ & $98.0 \pm 2.0 \mathrm{a}$ & $100.0 \mathrm{a}$ & $96.0 \pm 2.4 \mathrm{a}$ & $36.0 \pm 10.3^{\mathrm{e}}$ & $71.4 \pm 7.2$ & $60.0 \pm 10.5$ & $70.2 \pm 6.5$ \\
\hline
\end{tabular}

${ }^{\mathrm{a}}$ Each mean is based on $n=5$.

${ }^{\mathrm{b}}$ For each strain and response (knockdown or mortality), means among rates followed by different letters are significantly different ( $P$ $<0.05$; by least squares means test). 
${ }^{\mathrm{c}}$ For each $T$. castaneum strain, knockdown among rates was not significant $(F$, range among strains $=0.76-2.67 ; \mathrm{df}=3,16 ; P$, range $=0.083-0.532$; one-way ANOVA).

${ }^{\mathrm{d}}$ For T. castaneum Lab., CF, or PD1 strain, mortality among rates was not significant $(F$, range among strains $=0.91-2.11 ; \mathrm{df}=3,16$; $P$, range $=0.139-0.459$; one-way ANOVA)

${ }^{\mathrm{e}}$ For $O$. surinamensis $\mathrm{AB} 1$ or AB2 strain, mortality among rates was not significant $(F$, range between strains $=1.22-2.62 ; \mathrm{df}=3,16$; $P$, range $=0.087-0.336$; one-way ANOVA) 


\section{Figure captions}

Figure 1. Mean $\pm \operatorname{SE}(n=3)$ observed and predicted adult knockdown and mortality of laboratory strains of three insect species as a function of time when exposed to $\beta$-cyfluthrin and chlorpyrifos-methyl plus deltamethrin treated concrete surfaces at $24.3^{\circ} \mathrm{C}$ and $23.4 \%$ r.h.

Figure 2. Mean \pm SE $(n=5)$ knockdown and mortality of adults of laboratory and field strains of three insect species exposed to $\beta$-cyfluthrin and chlorpyrifos-methyl plus deltamethrin treated concrete surfaces at room conditions $\left(25.4^{\circ} \mathrm{C}\right.$ and $17.2 \%$ r.h.) For each species and response, means for a strain followed by an asterisk $(*)$ is significantly different from the corresponding laboratory strain $(P<0.05$; by Dunnett's test $)$.

Figure 3. Mean \pm SE $(n=5)$ knockdown and mortality of adults of laboratory and field strains of three insect species exposed to $\beta$-cyfluthrin and chlorpyrifos-methyl plus deltamethrin treated concrete surfaces at constant conditions $\left(28^{\circ} \mathrm{C}\right.$ and $65 \%$ r.h.). For each species and response, means for a strain followed by an asterisk $(*)$ is significantly different from the corresponding laboratory strain $(P<0.05$; by Dunnett's test $)$. 
A

B
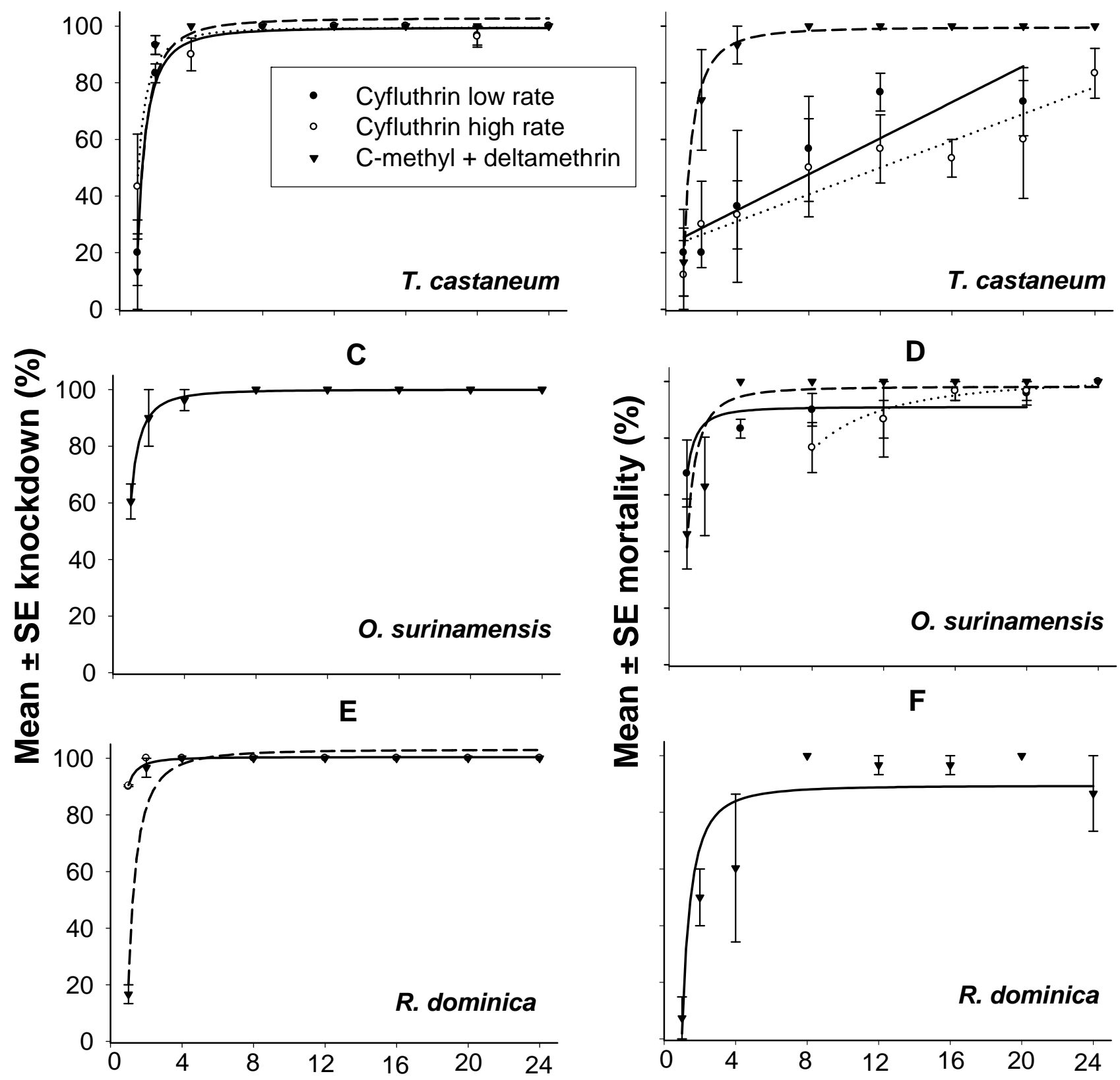

Time (h) 
Figure 2

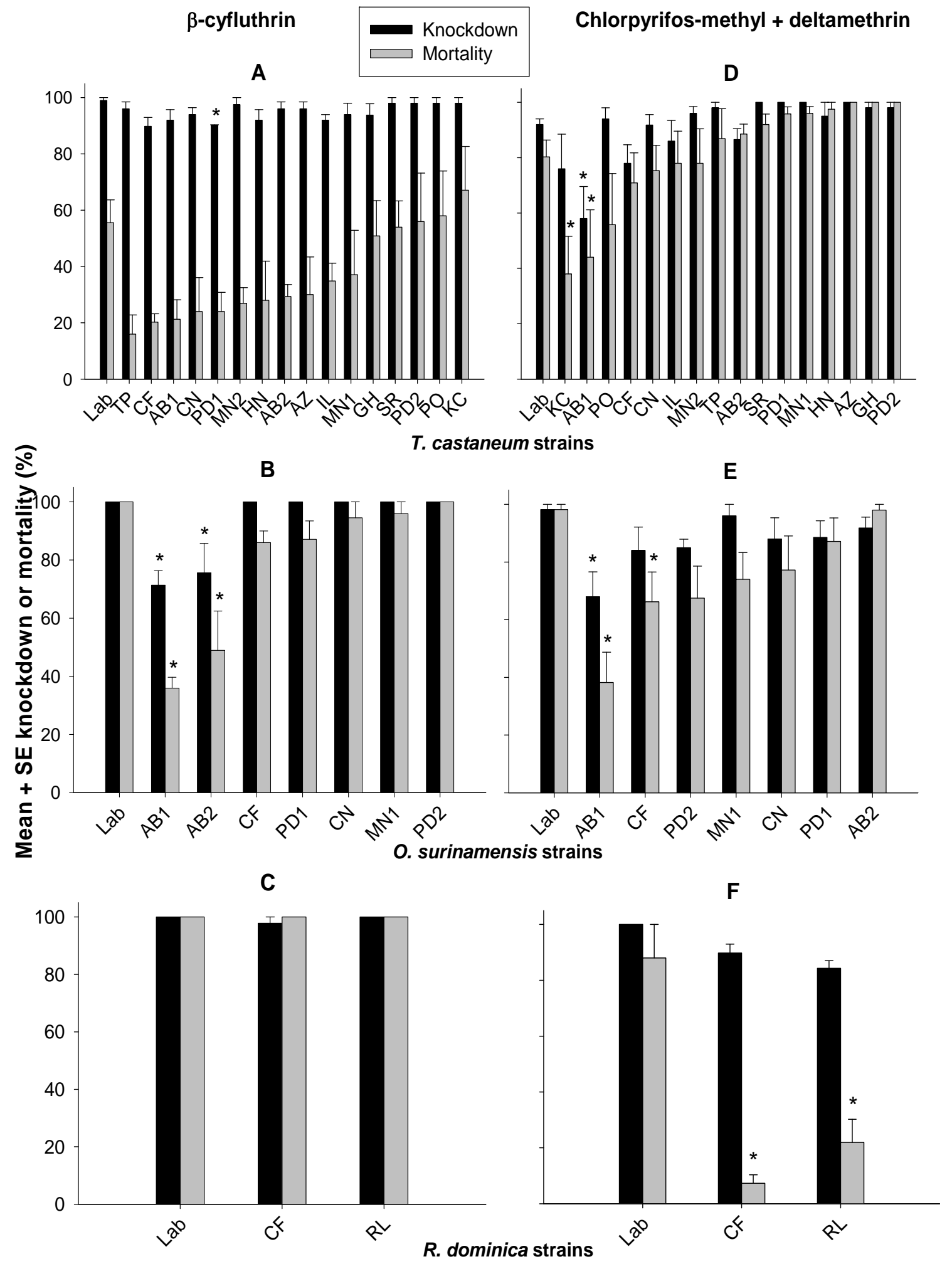


Figure 3

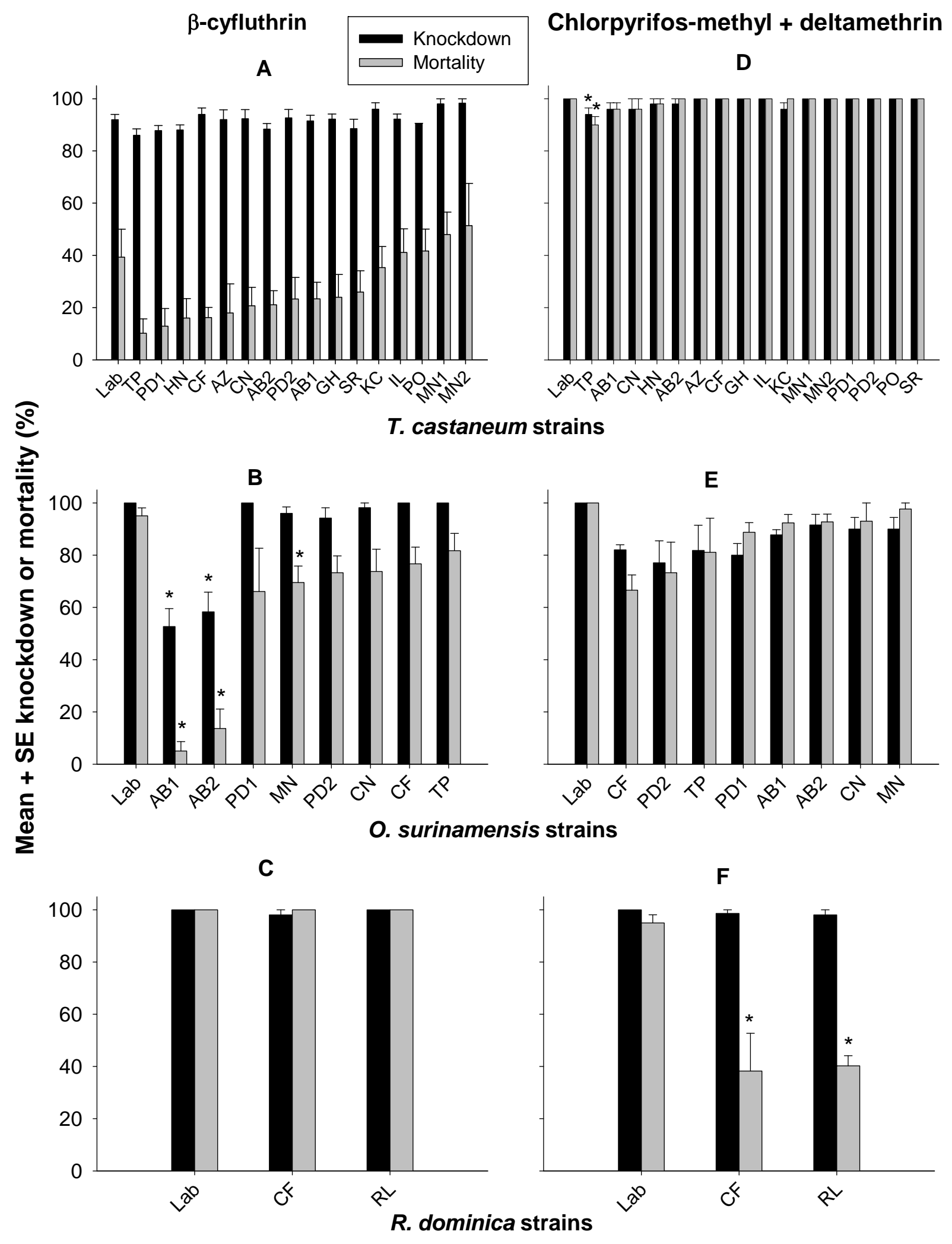

